Www.jmscr.igmpublication.org

Index Copernicus Value: 79.54

ISSN (e)-2347-176x ISSN (p) 2455-0450

crossref DOI: https://dx.doi.org/10.18535/jmscr/v7i6.49

\title{
Premedication with Midazolam in Children: A Randomised Control Study between Oral and Intranasal Routes
}

Authors

\section{Dr Neetika Mishra M.D ${ }^{1^{*}}$, Dr Mhonbemo Khuvung M.D², Dr Sunil Kumar Sah ${ }^{3}$ Dr Ahito kibami M.B.B.S}

${ }^{1}$ Associate Professor, Dept. of Anaesthesiology, North Bengal Medical College, Darjeeling, West Bengal ${ }^{2}$ Consultant Anaesthesiologist, Navjeevan Hospital \& Rural health care centre, Darjeeling, West Bengal ${ }^{3}$ Assistant Professor, Dept. of Anaesthesiology, North Bengal Medical College, Darjeeling, West Bengal ${ }^{4}$ Post Graduate trainee, Dept. of Anaesthesiology, North Bengal Medical College, Darjeeling, West Bengal

*Corresponding Author

Dr Neetika Mishra M.D

Associate Professor, Dept. of Anaesthesiology, North Bengal Medical College, Darjeeling, West Bengal

\section{Introduction}

Children posted for surgery are often anxious and uncooperative due to the anticipation of pain, unfamiliar environment, parental separation and fear as a result of previous unpleasant experiences $^{(1)}$. It is always an emotionally stressful and difficult moment for both the child and the mother. Anxiety in children undergoing surgery is characterized by the subjective feeling of tension, apprehension and nervousness. Anxiety is seen in almost all the paediatric patients.

Preoperative anxiety stimulates the sympathetic nervous system and endocrine system leading to an increase in the heart rate and blood pressure which reflects the fear and anxiety of a child from parental separation, physical harm, surgical instruments and hospital procedures. This may lead to post-operative psychological and behavioural problems, such as new onset enuresis, feeding difficulties, apathy, withdrawal, and sleep disturbances ${ }^{(2)}$. Separation anxiety usually begins at 7-8 months of age and peaks around 1 year of age. The extent of trauma or adaptive responses depends on the child's developmental age, parenting experiences, genetic endowment, and environmental stability. The intensity of separation anxiety declines with age.

Preoperative anxiety also activates the human stress response, leading to increase in serum cortisol, epinephrine, and natural killer cell activity ${ }^{(3-5)}$. This stress response can be activated by many different noxious stimuli including fear, anxiety, pain, cold, major surgery, and infection. Stress activates the hypothalamic pituitary-adrenal axis thus increases the circulating glucocorticoids and is associated with the alterations of immune function and susceptibility to infection and neoplastic diseases. Controlling these metabolic reactions is a necessity in modern anaesthesia practise $^{6}$. Smooth induction and maintenance can be achieved by controlling anxiety. Studies published in the Health-Psychology literature suggest that increased preoperative anxiety is 
associated with poor post-operative behavioural and clinical recovery ${ }^{(7-10)}$. Decrease in the perioperative hormonal response is likely to result in the decrease of catabolic response and improve the wound healing, thereby an improved postoperative clinical course ${ }^{(11)}$. Thus, the consensus is evident among the anaesthesiologists about the need to treat anxiety before surgery. These behavioural preparation programs have evolved significantly over recent decades.

Currently, development of coping skills is considered the most effective preoperative preparation intervention, followed by modelling, play therapy, operating room tour, and printed material. Psychological preparation programs should also be tailored to individual needs such as age, developmental stage, and previous experiences.

Anxiety due to parental separation can also be reduced by allowing the presence of the parent in the operating room. Presence of a parent during premedication with midazolam has been shown to be effective in reducing the anxiety. Pharmacological modalities available to treat preoperative anxiety are benzodiazepines, opioids and antihistamines, with benzodiazepines being the most frequently used drug.

Finding a suitable pre-medicant for children and the best route of administration is something that has been investigated for a long time. The ideal preparation should have an acceptable, atraumatic route of administration as well as produce the desired clinical effect.

Midazolam was introduced into the clinical practice during the 1980s. Oral premedication with midazolam is commonly used in paediatric anaesthesia in reducing preoperative anxiety, producing sedation and ensuring smooth separation from parents and inducing anaesthesia. Midazolam is a water-soluble benzodiazepine with an imidazole ring which is a short-acting and is absorbed rapidly. Midazolam has been used as a pre-medicant ${ }^{(15-16)}$ through different routes like the intravenous, intramuscular, intranasal, oral and rectal routes. It is commonly used for its protective effect against the negative postoperative behaviours like anxiety and nightmares ${ }^{(17)}$.

Oral midazolam is commonly used as it is easy to administer in children but the acceptability is less due to its bitter taste and its onset of action is also slower compared to the intramuscular and intranasal routes ${ }^{(18)}$. Intramuscular injection causes pain and also the fear of the needle results in poor acceptability, sublingual route has a poor compliance. Rectal midazolam is effective with a better success rate, but takes a longer time to produce an effect and also it is less acceptable particularly in older children because of modesty issue $^{(19)}$.

Administration of a drug as nasal spray is relatively easier, especially if the child is sitting on the parent's lap or 'being cuddled'. In some circumstances it is even possible for the parent to administer the spray with a doctor in attendance. Intranasal midazolam has a faster onset of action than other routes and is easy to administer but it causes nasal stinging and irritation ${ }^{(20)}$. In the present study we hypothesize that children receiving intranasal midazolam will have a better quality of sedation and cooperativeness as compared to those receiving oral midazolam.

\section{Materials and Methods}

The prospective randomised control study was conducted after getting approval from the Hospital Ethic Committee in children between age of 3 to 6 years complying to ASA I and ASA II scheduled for elective surgeries. Patient with URTI, airway problems, history of allergy to any of the drugs used in the study, body weight less than $10 \mathrm{~kg}$ or above $20 \mathrm{~kg}$, with any significant cardiovascular and pulmonary disease were excluded from the study. Patient who were not willing to take the medications or spit out after administration were also excluded from the study.

Considering a difference of $35 \%$ in cooperativeness in patients receiving intranasal midazolam $(0.2 \mathrm{mg} / \mathrm{kg})$ and oral midazolam $(0.5$ $\mathrm{mg} / \mathrm{kg}$ ) from previous studies, assuming the alpha 
risk at $5 \%$ and power of the study at 0.8 the sample size in each group came out to be 33. Keeping the possibility of drop-out to be $10 \%$, sample size of 74 patients was considered. The patients were randomly divided into 2 groups: Group A for those receiving oral midazolam and Group B for those receiving midazolam intranasally.

During preoperative visit on the day before surgery, the patient's parents were thoroughly explained about the procedure to be undertaken and the risks and benefits associated with it (informed consent). Vital parameters were recorded. Parents were advised to keep the child overnight fasting for solid food and clear liquid to be allowed till 2 hours before surgery.

The patient was transferred to the procedure room on scheduled time and lactated ringer's solution was started through an intravenous line on the non-dominant hand. Monitors were attached to the patient and the baseline vital parameters were measured. The body weight of each patient was taken beforehand. In the procedure room patients are accompanied by their parents. One trained observer blinded to the route of administration score all the patients before premedication was administered (baseline), during the drug administration and after premedication at the interval of 5 minutes till the parental separation at 20 minutes to assess sedation and cooperativeness. A pulse oximeter was attached to the patient and back-up monitors such as ECG, Capnometer were kept ready in the procedure room along with anaesthesia machine, airway of different sizes, endotracheal tube, paediatric breathing circuit, mask and laryngoscopes to combat any event of respiratory depression and hypoxia.

Injectable preparation of midazolam $(5 \mathrm{mg} / \mathrm{ml}$ ampoule preservative free) mixed with equal volume of apple juice (to make it palatable) was administered as oral drops, the dose of oral midazolam was $0.5 \mathrm{mg} / \mathrm{kg}$ of body weight. Midazolam nasal spray (by the tradename INSED atomiser) with each metered-dose of $100 \mu 1$ delivering $0.5 \mathrm{mg}$ of midazolam was administered in both nostrils of children allocated to receive through intranasal route, the dose of intranasal midazolam was $0.25 \mathrm{mg} / \mathrm{kg}$ body weight.

The blinded observer received thorough of the study scale to be used and had adequate training and skill to revive a child if any event of respiratory depression or hypoxia occurs.

\section{The child cooperativeness during drug} administration is assessed by using a 3-point scale:

$1=$ fully cooperative, unafraid or asleep

$2=$ mild to moderate fear and/or crying which ceases and the child becomes cooperative with assurance

$3=$ uncooperative, crying, inconsolable.

\section{Quality of sedation were assessed by Ramsay} sedation scale;

$1=$ patient is anxious and agitated or restless, or both

$2=$ cooperative, oriented and tranquil,

$3=$ responds to command only

$4=$ exhibit brisk response to light glabellar tap or loud auditory stimulus

$5=$ exhibit a sluggish response to light glabellar tap or loud auditory stimulus

$6=$ patient exhibits no response

Parent's satisfaction with the premedication given to their children were also assessed:

$1=$ not satisfied.

$2=$ good, satisfied.

$3=$ excellent, very satisfied.

\section{Results and Analysis}

Initially, 74 patients undergoing surgery under general anaesthesia were included in the study with 8 patients among them refused to give consent. So, the remaining 66 patients were randomised into two groups to receive oral midazolam or intranasal midazolam.

After completion of study, recorded data were unfolded, tabulated and analysed statistically. Discrete categorical data are presented as $\mathrm{n}(\%)$ 
and median; continuous data are given as mean \pm SD. Differences in demographic data, vital parameters and cough were tested by Independentsamples t test (continuous data) or by Pearson Chi- square as appropriate (categorical data). For descriptive purposes, $\mathrm{p}$ value $<0.05$ was considered statistically significant. All analysis was conducted using SPSS for Windows (version 12).

Table 1 Demographic Parameters

\begin{tabular}{|l|c|c|c|}
\hline Parameters & $\begin{array}{c}\text { Group } \\
\mathbf{A}(\mathbf{n}=\mathbf{3 3})\end{array}$ & $\begin{array}{c}\text { Group } \\
\mathbf{B}(\mathbf{n}=\mathbf{3 3})\end{array}$ & p-value \\
\hline Age (years) & $6 \pm 2.1$ & $5.5 \pm 2.15$ & $0.912(\mathrm{NS})$ \\
\hline Sex (M:F) & $25: 8$ & $26: 7$ & $0.564(\mathrm{NS})$ \\
\hline Wt. (kg) & $16.8 \pm 4.2$ & $15.9 \pm 4.1$ & $0.929(\mathrm{NS})$ \\
\hline DOS (min) & $47.5 \pm 17.9$ & $42.4 \pm 15.9$ & $0.317(\mathrm{NS})$ \\
\hline
\end{tabular}

$(p<0.05=$ significant $),{ }^{*}$ Pearson Chi-square test used, results are presented as number of patients. For others, Independent-samples $t$ test used, results are presented as mean \pm SD. Group A- oral group; Group B- Intranasal group. NS- non significant.

Table 1 is showing demographic characteristics. All the values are statistically insignificant $(p<0.05)$ when compared between groups. Mean age of patients in group A was $6 \pm 2.1$ years which was comparable $(p=0.912)$ with mean age of patients in group B (5.5 \pm 2.15 years). Average weight of patients in groups were $16.8 \pm 4.2 \mathrm{~kg}$ and $15.9 \pm 4.1 \mathrm{~kg}$ in group A and B respectively, which was also comparable $(p=0.929)$. Sex distribution was also comparable $(p=0.564)$. so patients in two groups were comparable regarding demographic characteristics.

Table 2a Ramsay sedation score

\begin{tabular}{|l|c|c|c|}
\hline Time & $\begin{array}{c}\text { Ramsay } \\
\text { sedation } \\
\text { score }\end{array}$ & $\begin{array}{c}\text { Group A(no. } \\
\text { of patients) }\end{array}$ & $\begin{array}{c}\text { Group B (no. } \\
\text { of patients) }\end{array}$ \\
\hline Baseline & 1 & 6 & 10 \\
& 2 & 27 & 23 \\
& 3 & 0 & 0 \\
\hline 5mins & 1 & 27 & 26 \\
& 2 & 6 & 7 \\
& 3 & 0 & 0 \\
\hline 10mins & 1 & 11 & 4 \\
& 2 & 22 & 28 \\
\hline
\end{tabular}

\begin{tabular}{|l|c|c|c|}
\hline & 3 & 0 & 1 \\
\hline 15 mins & 1 & 0 & 0 \\
& 2 & 15 & 9 \\
& 3 & 18 & 24 \\
\hline 20 mins & 1 & 0 & 0 \\
& 2 & 10 & 5 \\
& 3 & 23 & 28 \\
\hline During & 1 & 5 & 4 \\
induction & 2 & 10 & 8 \\
& 3 & 18 & 21 \\
\hline
\end{tabular}

Fig.2a. shows the comparison of the number of patients in each group (Group A- oral midazolam; Group B- intranasal midazolam) attaining the level of sedation at different time point assessment.

Table 2b Ramsay sedation score

\begin{tabular}{|l|ll|l|}
\hline Time & \multicolumn{2}{|c|}{ Ramsay sedation score } & $p$-value \\
& Group A & Group B & \\
\hline Baseline & $1.81 \pm 0.39$ & $1.69 \pm 0.46$ & 0.000 \\
\hline $\begin{array}{l}5 \text { mins after } \\
\text { premedication }\end{array}$ & $1.18 \pm 0.39$ & $1.21 \pm 0.41$ & 0.000 \\
\hline $\begin{array}{l}\text { 10mins after } \\
\text { premedication }\end{array}$ & $1.66 \pm 0.47$ & $1.90 \pm 0.38$ & 0.000 \\
\hline $\begin{array}{l}15 \text { mins after } \\
\text { premedication }\end{array}$ & $2.54 \pm 0.50$ & $2.72 \pm 0.45$ & 0.027 \\
\hline $\begin{array}{l}\text { 20mins after } \\
\text { premedication }\end{array}$ & $2.69 \pm 0.46$ & $2.84 \pm 0.36$ & 0.000 \\
\hline During induction & $2.39 \pm 0.74$ & $2.51 \pm 0.71$ & 0.000 \\
\hline
\end{tabular}

( $p<0.05=$ significant), Pearson Chi-square test used, results are presented as mean $\pm \mathrm{SD}$, Group A- oral midazolam; Group B- intranasal midazolam.

Table $2 \mathrm{~b}$. provides a summary of the level of sedation of the patients at each time points. After premedication, patients receiving intranasal midazolam $(0.25 \mathrm{mg} / \mathrm{kg})$ had a better sedation score (as assessed by Ramsay sedation score) than those patients receiving oral midazolam $(0.5$ $\mathrm{mg} / \mathrm{kg}$ ) and they were found to be statistically significant $\quad(p<0.05)$ at 20 mins after premedication, Group B patients were found to be more sedated $(3.84 \pm 0.36)$ at the time of separation from the mother and during induction of

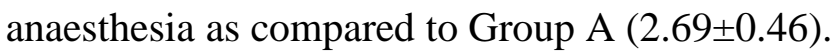


Table 3a Co-operativeness score

\begin{tabular}{|l|c|c|c|}
\hline Time & $\begin{array}{c}\text { Co- } \\
\text { operativeness } \\
\text { score }\end{array}$ & $\begin{array}{c}\text { Group A } \\
(\mathrm{n}=33)\end{array}$ & $\begin{array}{c}\text { Group B } \\
(\mathrm{n}=33)\end{array}$ \\
\hline Baseline & 1 & 28 & 28 \\
& 2 & 5 & 5 \\
Drug & 3 & 0 & 0 \\
\hline administration & 1 & 0 & 0 \\
& 2 & 18 & 7 \\
\hline 5mins & 1 & 15 & 26 \\
\hline 10mins & 2 & 13 & 0 \\
& 3 & 20 & 8 \\
& 1 & 1 & 25 \\
\hline 15mins & 2 & 28 & 31 \\
& 3 & 4 & 1 \\
\hline 20mins & 1 & 9 & 11 \\
& 3 & 24 & 22 \\
& 1 & 0 & 0 \\
\hline During & 2 & 20 & 26 \\
induction & 3 & 12 & 7 \\
& 2 & 18 & 0 \\
\hline
\end{tabular}

Table 3a shows the comparison of the number of patients in each group (Group A- oral midazolam; Group B- intranasal midazolam) attaining the score of co-operativeness at different time point assessment.

Table 3b Co-operativeness score

\begin{tabular}{|c|c|c|c|}
\hline \multirow[t]{2}{*}{ Time } & \multicolumn{2}{|c|}{ Co-operativeness score } & \multirow[t]{2}{*}{$p$-value } \\
\hline & Group A & Group B & \\
\hline Baseline & $1.15 \pm 0.36$ & $1.15 \pm 0.36$ & 0.000 \\
\hline $\begin{array}{ll}\text { During } & \text { drug } \\
\text { administration } & \\
\end{array}$ & $2.45 \pm 0.50$ & $2.78 \pm 0.41$ & 0.049 \\
\hline $\begin{array}{ll}\text { mins } & \text { after } \\
\text { premedication } & \\
\end{array}$ & $2.60 \pm 0.49$ & $2.75 \pm 0.43$ & 0.003 \\
\hline $\begin{array}{ll}\text { 10mins } & \text { after } \\
\text { premedication }\end{array}$ & $2.09 \pm 0.38$ & $2.00 \pm 0.25$ & 0.000 \\
\hline $\begin{array}{ll}15 \text { mins } & \text { after } \\
\text { premedication } & \\
\end{array}$ & $1.72 \pm 0.45$ & $1.66 \pm 0.47$ & 0.001 \\
\hline $\begin{array}{ll}20 \text { mins } & \text { after } \\
\text { premedication } & \end{array}$ & $1.42 \pm 0.56$ & $1.21 \pm 0.41$ & 0.000 \\
\hline During induction & $1.45 \pm 0.56$ & $1.18 \pm 0.39$ & 0.003 \\
\hline
\end{tabular}

( $p<0.05=$ significant), Pearson Chi-square test used, results are presented as mean $\pm \mathrm{SD}$, Group Aoral midazolam; Group B- intranasal midazolam.

Table 3b. provides a summary of the cooperativeness of the patient at each of the assessment time points. It was found that during the administration of the drug, both the groups had a higher score in most of the patients though they were statistically significant $(p<0.049)$. in the following time points assessment the cooperativeness score shows improvement and the two groups were found to be statistically significant $(p<0.05)$. at 20 mins patients receiving intranasal midazolam $(1.21 \pm 0.41)$ has a better cooperativeness score than patients receiving oral midazolam (1.42 \pm 0.56$)$.

Table 4 Parent's satisfaction score

\begin{tabular}{|l|c|c|}
\hline $\begin{array}{l}\text { Parent's } \\
\text { satisfaction score }\end{array}$ & $\begin{array}{c}\text { Group A } \\
\text { no. of patient }(\%)\end{array}$ & $\begin{array}{c}\text { Group B } \\
\text { no. of patient }(\%)\end{array}$ \\
\hline 1 (not satisfied) & $2(3 \%)$ & $1(1.5 \%)$ \\
\hline 2 (good, satisfied) & $27(40.90 \%)$ & $25(37.87 \%)$ \\
\hline 3 (excellent) & $4(6 \%)$ & $7(10.60 \%)$ \\
\hline
\end{tabular}

Group A- oral midazolam; Group B- intranasal midazolam

Table 4. shows the assessment of parent's satisfaction with the method used for administrating the drug and the co-operativeness of the patient. Parent's satisfaction with the scoring 1 (not satisfied) shows no much difference between the two groups (3\% in Group A and 1.5\% in Group B), parent's scoring 2 (good, satisfied) was seen to be slightly higher in Group A (40.90\%) than in Group B (37.87\%). Whereas parent's satisfaction of score 3 was higher in patients receiving intranasal midazolam ie. Group B $(10.60 \%)$ as compared to patients receiving oral midazolam ie. Group A (6\%).

Table 5. Incidence of adverse events

\begin{tabular}{|l|c|c|}
\hline Adverse events & $\begin{array}{c}\text { Group A (no. } \\
\text { of patient) }\end{array}$ & $\begin{array}{c}\text { Group B (no. } \\
\text { of patient) }\end{array}$ \\
\hline Nausea & 2 & 1 \\
\hline Vomiting & 2 & 0 \\
\hline Bradycardia & 0 & 0 \\
\hline Respiratory depression & 0 & 0 \\
\hline Hypotension & 0 & 0 \\
\hline
\end{tabular}

Table 5 shows the adverse effects in both the groups. There were no serious adverse events, although nausea and vomiting were seen in patients receiving both oral and intranasal midazolam (2 patients each) . No patient received flumazenil to reverse sedation.

\section{Discussion}

Most of the children suffers from severe anxiety and apprehension when they are separated from 
their parents or family members and are often uncooperative due to anticipation of pain, an unfamiliar environment, parental separation or a previous unpleasant experience.

This lack of cooperation may be the result of anxiety that has been shown to be associated with an increased level of post-operative pain and the release of stress hormones which may lead to negative outcomes. In addition, approximately half of the children demonstrate negative behaviours post-operatively, which are partially predicted by patient's anxiety at induction and previous bad hospital experiences.

The pre-operative anxiety is two-fold in children without pre-medications in comparison to premedicated children. Children when pre-medicated properly are separated from their parents without anxiety, this psychological effect attenuate autonomic reflexes, prevent excessive secretion in airway, allays anxiety, facilitates smooth induction of anaesthesia and reduce the dosage of anaesthetics. Hence, all the paediatric patients are to be pre-medicated in order to decrease preoperative anxiety which allows smooth induction and thus results in minimal post-operative psychological insult and behaviour changes ${ }^{(43,44)}$.Premedication with midazolam has been shown to be a safe and effective drug in children undergoing operative procedures. It can be administered by various routes like intramuscular, oral, rectal, intranasal and sublingual. The beneficial effects of midazolam include sedation, anxiolysis and reduction of post- operative vomiting. There are advantages and disadvantages to each method of administration. Intramuscular administration is rarely utilized because although it produces rapid onset, the needle insertion is painful. Oral administration is the most common and least invasive, but requires patient's cooperation. Although oral preparations are available, midazolam has a bitter taste which is not easily disguised and often rejected by small children. Rectal administration of midazolam, though effective, is not accepted in some cultures and by older children. Larger doses are required for rectal route, onset time is slower, and absorption may be erratic. Nasal midazolam is easier to administer but it causes nasal stinging, burning and discomfort ${ }^{(1)}$.

In the present study, sixty-six patients of either sex of age between 3 and 6 years complying to ASA I and II criteria, posted for surgery (surgical or orthopaedic) were randomly divided into two groups of thirty-three each.

Patients belonging to group A received intranasal midazolam $(0.05 \mathrm{mg} / \mathrm{kg})$ and group $B$ received intranasal midazolam $(0.25 \mathrm{mg} / \mathrm{kg})$ twenty minutes prior to induction of anaesthesia. In the procedure room patients are accompanied by their parents. One trained observer blinded to the route of administration scored all the patients before premedication was administered (baseline), just after the drug administration and after premedication at an interval of five minutes till the parental separation at twenty minutes to assess the sedation and cooperativeness.

After assessing the demographic profiles of the above groups, it was found that the mean age of the children were ( $6 \pm 2.1$ years) in group $\mathrm{A}$ and $(5.5 \pm 2.15)$ in group B. There was no statistically significant difference observed in age, weight, and duration of surgery between two group (A and B) (Table 1).

Each group was studied for the onset of sedation, cooperativeness score and any adverse events. We studied the quality of onset of sedation using the Ramsay sedation score (score 1 to 6 ) up-to twenty minutes at an interval of 5 minutes each.

We found that patients receiving intranasal midazolam $(0.25 \mathrm{mg} / \mathrm{kg})$ had a better sedation score than those receiving intranasal midazolam $(0.05 \mathrm{mg} / \mathrm{kg})$ and they were found to be statistically significant $(p<0.05)$. At 20 minutes after premedication, group B (intranasal midazolam) patients were found to be more sedated (2.84 \pm 0.36$)$ as compared to group A (oral midazolam) $(2.69 \pm 0.46)$ and statistically significant $(p<0.05)$.

In a study by Klein et al. ${ }^{(40)}$ in 2011 , found that patients receiving intranasal midazolam had a 
faster onset of sedation as compared to patients receiving oral midazolam.

Similarly in a study by Alexander K et al. ${ }^{(23)}$ they found that sedation and anxiolysis increased with time, achieving a maximum at $20 \mathrm{~min}$ to $30 \mathrm{~min}$, with intranasal route providing a faster effect. Patient mask acceptance was good for more than $75 \%$ of the children.

Patient' cooperativeness score was assessed using a 3-point scale.

During the administration of drug, most patients in each group had a higher score (score 3); with patients receiving intranasal midazolam scoring higher $(2.78 \pm 0.41)$ as compared to receiving oral midazolam $(2.45 \pm 0.50)$ though they were statistically significant ( $p$ 0.049). the cooperativeness score improved significantly with each time point at 5 mins ( $p 0.003), 10$ mins $(p 0.00), 15 \operatorname{mins}(p 0.001)$ and $20 \operatorname{mins}(p 0.00)$ after premedication and during induction ( $p$ 0.003). At 20 mins patients receiving intranasal midazolam $(1.21 \pm 0.41)$ had a better cooperativeness score than patients receiving oral midazolam $(1.42 \pm 0.56)$ as shown in table 3 and figure 3.

Chhibber AK et al. ${ }^{(1)}$ compared among oral, intranasal, rectal administration of midazolam and concluded that cooperativeness scores among the three groups differed significantly at the time of drug administration $\quad(p<0.001)$ rectal administration results in more cooperativeness than the nasal route $(p<0.001=0.014,<0.001$, respectively) and oral route ( $p 0.019,0.022$, and 0.002 , respectively). The rectal group had similar cooperativeness to baseline at administration, while the nasal and oral groups were less cooperative at administration than at baseline.

On assessing the overall patients' satisfaction between the two groups using a 3 point scale (table 3 and fig.3a,b), it was found that parents giving a score of 1 (not satisfied) showed no much difference between the two groups (3\% in Group A and $1.5 \%$ in Group B), parents scoring 2 (good, satisfied) was seen to be slightly higher in Group A (40.90\%) than in Group B(37.87). Whereas patient's satisfaction of score 3 was higher in patients receiving intranasal midazolam ie Group $\mathrm{B}(10.60 \%)$ as compared to patient's receiving oral midazolam ie Group A (6\%).

In previous studies done by Bhakta $\mathrm{P}$ et al. ${ }^{(20)}$ and Davis PJ et al. ${ }^{(35)}$, similar observations were noted as they found satisfactory parental separation and a satisfactory induction over $70 \%$ of the time and did not prolong recovery time and hospital discharge.

Malinovsky et al. ${ }^{(45)}$ also found that intranasal midazolam is an excellent method for premedication compared to the oral and rectal routes. Hollenhorst $\mathbf{J}$ et al. ${ }^{(28)}$ also found that patients receiving intranasal midazolam were more sedated and less anxious before entering MRI scanner, but reported a slight transient burning of the nasal mucosa.

Karl HW et al. ${ }^{(27)}$ found that child- parent separation to be satisfactory in $85 \%$ children receiving sublingual midazolam, and a satisfactory response to induction in $81 \%$ of the patients. Wilton $\mathrm{N}$ et al. ${ }^{(46)}$ found $60 \%$ of the patients receiving normal saline as premedication to be agitated during induction, as compared to $3 \%$ of those receiving midazolam.

As intranasal midazolam causes irritation and burning of the nasal mucosa, this could explain in the decrease of the score of 2 (good, satisfied) ie., $37.87 \%$ in Group B as compared to Group A $40.90 \%$. So the acceptance rate was low as also reported in literature ${ }^{(47)}$.Whereas patients' satisfaction of score 3 (excellent) was seen to be higher in patients receiving intranasal midazolam $(10.60 \%)$ as compared to those receiving oral midazolam $(6 \%)$, as the onset of sedation was seen to be faster and the degree of movement and crying were consistently lower in this group, this result was found to be similar in a study by Klein et al. ${ }^{(40)}$ where intranasal route demonstrated a greater number of patients with optimal activity scores and greater proportions of parents wanting similar sedation in the future and faster onset. But was also the most poorly tolerated at administration. 
Chhibber KA et al. ${ }^{(1)}$ and Griffith $\mathrm{N}$ et al. ${ }^{(33)}$ also reported similar findings in patients receiving intranasal midazolam complaining of nasal stinging and les cooperativeness during administration of the drug.

Though there are several reports of satisfactory acceptance of intranasal route ${ }^{(46,48,49)}$. Though the limited acceptance in our study was limited by crying, but most of the children later accepted it as persuasion. Sometimes the children accepted it when their mothers administered it.

Adverse events complaining of nausea and vomiting were noted in two patients each of those receiving oral midazolam whereas only one patient complained of nausea in the intranasal route. There were no adverse events like bradycardia, respiratory depression and hypotension.

Though in studies done by Chhibber et al. ${ }^{(1)}$ and Fishbein et al. ${ }^{(50)}$ it was found that nasal administration was poorly accepted causing pain and irritation, and resulted in nosebleed in some patients.

We accept the fact that there are some major drawbacks in the present study. First of all the sample size was very small to have a significant power of analysis. We have studied only the patients in 3-6 years age group scheduled for elective surgeries. In most of the studies with larger sample size, they have selected much wider age group. But we selected this special section of age group as they suffer the most from anxiety and apprehension ${ }^{(51)}$

In some literatures there are reports of studies done with lower sample size than ours where they have reported statistically significant result ${ }^{(52,53)}$. Therefore, what should be the minimum sample size in a study to have a significant result is the most uncertain part in statistics.

Another drawback is that, evaluation of recovery parameters was not our primary goal in the study. In this study the premedication period was 20 minutes for both oral and intranasal groups; however, in some children they were transferred to the OR slightly later than the predetermined time period due to some delay in the normal OR schedule. So, there are chances of unsatisfactory sedation at separation from parents and during induction of anaesthesia. It was also found that some children became distressed when they were aroused at the induction of anaesthesia, despite being very much sedated at the time of parental separation. Therefore, anaesthetic technique may need to be adjusted to provide an optimal condition for induction in children.

\section{Conclusion}

In children undergoing surgical procedure under anaesthesia, intranasal administration of midazolam as compared to oral routes, provides a better quality of onset of sedation and more effective at alleviating perioperative uncooperativeness.

\section{References}

1. Chhibber KA, Fickling K, Lustik JS. PreAnaesthetic Midazolam: A Randomized Trial with Three Different Routes of Administration; J Anaesthe Clinic Res 2011; 2:1.9993.

2. Kain ZN. Perioperative psychological trauma in children. In: Complications in Anaesthesia. $1^{\text {st }}$ Edition. W.B. Saunders Company. Philadelphia 1999.

3. Price D: Preoperative emotional states and adrenal cortical activity : Studies on Cardiac and pulmonary patients. Arch NeurolPsychiatr 1957; 77:646- 56.

4. Rogers M, Reich P: Psychological intervention with surgical patients: Evaluation outcome, Psychological Aspects of Surgery. Edited by Fava G, Guggenheim FG, Lipowski ZJ, Nemiah JC, Reich P, Engel GL, Levi L, Reichsmann F. Basel, Karger, 1986, pp 23-50.

5. Zhou D, Kusnecov AW, Shurin MR, DePaoli M, Rabin BS: Exposure to physical and psychological stressors elevates plasma interleukin6: Relationship 
to the activation of hypothalamicpituitary- adrenal axis. Endocrinology 1993; 133:2523-30

6. Roizen MF. Should we all have a sympathectomy at birth? Or atleastpreoperatively?; Anaesthesiology. 1988;68:482-4.

7. Wallace LM: Preoperative state anxiety as a mediator of psychological adjustment to and recovery from surgery. $\mathrm{Br} \mathrm{J}$ Med Psyhol1986;59:253-61.

8. Johnston M: Preoperative emotional states and post-operative recovery. Adv Psychosom Med 1986 15:1-22

9. Johnson J, Dabbs J, Leventhal $\mathrm{H}$ : Psychological factors in the welfare of surgical patients. Nurs Res 1970; 1918-28

10. Kiecolt - Glaser JK, Page G, Marucha P, MacCallum R, Glaser R: Psychological influences on surgical recovery. Am Psychologist 1998; 53; 1209-18

11. Weissman $C$ : The metabolic response to stress: An overview and update. Anaesthesiology 1990; 73: 308-27.

12. Splinter WM, MacNeill HB, Menard EA, Rhine EJ, Roberts DJ, Gould MH. Midazolam reduces vomiting after tonsillectomy in children. Can J Anaesth 1995; 42:201-3

13. Buffett - Jerrott SE, Stewart SH, Finley GA, Loughlan HL. Effects of benzodiazepines on explicit memory in a paediatric surgery setting. Psychopharmacology

(Berl) 2003;168:m377-86.

14. Marshall J,Rodarte A, Blumer J, Akbari B, Kearns G. Paediatric pharmacodynamics of midazolam oral syrup. Pediatric Pharmacology Rsearch Unit Network. J Clin Pharmacol 2000; 40:578-89.

15. Kain ZN, Caldwell- Andrews AA, Krivutza DM, Weilberg ME, S-M, Gaal D. Trends in the practice of parental presence during induction of anaesthesia and the use of preoperative sedative premedication in the United States, 1995-2002: results of a follow- up national survey. AnesthAnalg 2004; 98:1252-9.

16. Kain ZN, Mayes L, Bell C, Weisman S, Hofstadter M, Rimar S. Premedication in the United States: a status report. AnesthAnalg 1997; 84:527-32.

17. Almenrader N, Passriello M, Coccetti B, Haiberger $\mathrm{R}$ et al. premedication in children: a comparison of oral midazolam and oral clonidine; Pediatric Anaesthesia 2007; 17: 1143-9.

18. Al - Rakaf H, Bello LL, Turkustani A, Adenubi JO: Intranasal midazolam in conscious sedation of young pediatric dental patient; International Journal of Pediatric Dentistry 2001; 11:33-40.

19. Kogan A, Katz J, Efrat $R$ et al. Premadication with midazolam in young children: a comparison of four routes of administration. Paediatr Anaesthesia 2002;12:685-9.

20. Bhakta P, Ghosh BR, Roy M, Mukherjee G. Evaluation of intranasal midazolam for preanaesthetic sedation in pediatric patients; Indian J Anaesth 2007; 51:111.

21. Stovner J, Enderson R. Diazepam in intravenous anaesthesia. Lancet 2:1298$1299,1965$.

22. Miller RD, Miller's Anaesthesia. Intravenous anaesthetics. $7^{\text {th }}$ edition. Churchill Livingstone Elseveir.2010.

23. Reves JG, Fragen RJ, Vinik HR, Greenblatt DJ. Midazolam: Pharmacology and uses. Anaesthesiology 62:310324, 1985.

24. Mohler DR, Fritschy JM, Rudolph U. A new benzodiazepine pharmacology. J Pharmacol EXP Ther 300:2-8,2002.

25. Amrein r, Hetzel W, Hartmann D, Lorsheid T. A clinical pharmacology of Flumazenil. Eur J AnaesthesiolSuppl 2:6580, 1988.

26. Griffith N, Howell S, Mason DG. Intranasal midazolam for premedication of 
children undergoing day-case anaesthesia: comparison of two delivery systems with assessment of intraobserver variability. $\mathrm{Br}$ J Anaesth1998;81:865-9.

27. Karl HW,Keifer AT, Rosenberger JL, Larach MG, Ruffle JM. Comparison of safety and efficacy of intranasal midazolam or sufentanyl for preinduction of anaesthesia on paediatric patients. Anaesthesiology 1999;76:209-15.

28. Hollenhorst $\mathbf{J}$ et al. Using intranasal midazolam spray to prevent claustrophobic induced by MRI 2000.

29. Kain $\mathrm{ZN}$ et al. Attenuation of the preoperative stress response with midazolam: effects on postoperative outcomes. Anaesthesiology 2000;93:1417.

30. Kain ZN et al. Midazolam: Effects on amnesia and anxiety in children. Anaesthesiology 2000;93:676-84.

Oral Midazolam Premedication in
preadolescents
Anaesthesia and analgesia 2001.

32. Alexander $\mathrm{K}$ et al. Premedication with midazolam in young children: a comparison of four routes of administration. Paediatric Anaesthesia 2002:12(8): 685-9.

33. Cote CJ, Cohen IT, Suresh S, Rabb M, Rose JB, Weldon C, Davis PJ, Bikhazi GB, Karl HW, Hummer KA, Hannallah RS, Khoo KC, Collins P. A comparison of three doses of commercially prepared oral midazolam syrup in children. AnaesthAnalg2002;94:37-43.

34. Lam C, Udin DR, Malamed FS, Good LD et al. Midazolam premedication in children: A Pilot study comparing intramuscular and intranasal administration. Anesth Prog 2005;52:5661.

35. Davis PJ, Tome JA, Mc Gowan FX Jr et al. Preanaesthetic medication with intranasal midazolam for very brief paediatric surgical procedure: effect on recovery and hospital discharge time. Anaesthesiology 1995;82:2-5.

36. R.K. Bailie, P Michalek,J.T. Doherty. Premedication with buccal midazolam in children and in adults with lesrning disabilities. Anaesthesiology 2007;62:53536.

37. Yuen VM et al. A comparison of intranasal dexmedetomidinenand oral midazolam for premedication in paediatric anaesthesia: A double blinded randomized controlled trial. Annual Scientific Meeting of the Australian and New Zealand College of Anaesthetics 2008.

38. Sheta SA, AlSarheed M. Oral midazolam premedication for children undergoing general anaesthesianfor dental surgery. Int J Pediatr2009;27:4380.

39. Feld LH, Negus JB, White PF. Oral midazolam preanaesthetic medication in paediatric outpatients. Anaesthesiology 1990;73:831-4.

40. Klein et al. A randomized clinical trial comparing oral, aerosolized, intranasal, and aerosolized buccal midazolam. Annuals of Emergency Medicine 2011;58(4):323-29.

41. Gupta S,GadaniH,Kedia S. Is premedication with midazolam more effective by sublingual route than the oral route?.Anaesth Essays Res 2011;5:43-7.

42. Darlong V et al. Low versus high- dose combination of midazolam- ketamine for oral premedication in children for ophthalmologic surgeries. Singapore Med J 2011;52(7):512.

43. Payne KA, Coetzee AR, Mattheyse FJ et al. Behavioural changes in children following minor surgery- is premedication beneficial ? Acta Anaesthesiol Belgium 1992;43:173.

44. Kain ZN, Mayes L, Wang SM et al. Effects of premedication on post - 
operative behavioural outcomes in children. Anaesthesiology 1997; 87:A1032.

45. Malinovsky JM, Populaire C, Cozain A, Lepage JY, Lejus C, et al. Premedication with midazolam in children - effect of intranasal, rectal nad oral routes on plasma midazolam concentrations. Anaesthesia 1995;50:351-54.

46. Wilton NC, Leigh J, Rosen DR, Pandit UA. Preanaesthetic sedation of preschool children using intranasal midazolam. Anaesthesiology 1988;69:972-5.

47. Karl HW, Rosenburger JH, Larach MG, Ruffle JM. Transmucosal administration of midazolam for premedication of paediatric patients. Comparison of nasal and sublingual routes. Anaesthesiology 1993;78:885-91.

48. Bojrkman S, Rigemar G, Idvall J. Pharmacokinetics of midazolam given a intranasal sprays to adult surgical patients. Br J Anaesth1997;79:575-80.

49. Vivarelli R, Zanotti F, Battagila D et al. Premedication with intranasal midazolam in children of various ages. Mineva Anaesthesiol 1998;64(11):499-504.

50. Fishbein M, Lugo RA, Woodland J, Lininger B, Linscheid T (1997). Evaluation of intranasal midazolam in children undergoing esophagogastroduodenoscopy. J Pediatr Gastroenterol Nutr 25:261-66.

51. Weksler N, Ovadia L, Muati G et al. Nasal ketamine for paediatric premedication. Can J Anesth1993;40:119-21.

52. Fukuta O, Braham RL, Yanasse $\mathrm{H}$ et al. Intranasal administration of midazolam: pharmacokinetic and pharmacodynamic properties and sedative potential. ASDC $\mathbf{J}$ Dent Child 1997(64): 89-98.
53. Malinovsky JM, Lejus C, Servin F et al. Plasma concentration of midazolam after intravenous, nasal or rectal administration in children. Br J Anesth 1993;70(6):61720. 